\title{
Reading as one of the significant language skills
}

\author{
Aripova Xalima Aripovna ${ }^{1}$ \\ ${ }^{1}$ Bukhara State University, Uzbekistan \\ Email:aripova x@umail.uz
}

\begin{abstract}
In article was written about developing of reading skill in language learning, importance of reading in language learning, main features of teaching reading in foreign languages.
\end{abstract}

Keywords: reading, reading skills, language learning, teaching languages, languages skills.

\section{INTRODUCTION}

Reading is one of the significant skills that plays great role in teaching and learning FL. Reading is an interactive process between the reader, the text and the context in which the text is presented. The most important component here is the reader. The reader gives meaning to the text, not the other way around. The reader's prior knowledge determines what meaning he will derive from his interaction with the text. But here, the context plays a big role as well since it sets the purpose or instruction for reading. The purpose for reading should be built on what the reader already knows, and then relate it to something that he needs to find out in the text. 1

When a person reads a text he engages in a complex array of cognitive processes. He is simultaneously using his awareness and understanding of phonemes (individual sound "pieces" in language), phonics (connection between letters and sounds and the relationship between sounds, letters and words) and ability to comprehend or construct meaning from the text. This last component of the act of reading is reading comprehension.

Reading comprehension is one of the pillars of the act of reading It cannot occur independent of the other two elements of the process. At the same time, it is the most difficult and most important of the three. Simply put, Reading comprehension is the act of understanding what you are reading. However it should not be simply understood as simple to teach, learn or practice. Reading comprehension is an intentional, active, interactive process that occurs before, during and after a person reads a particular piece of writing..

There are two elements that make up the process of reading comprehension: vocabulary knowledge and text comprehension. In order to understand a text the reader must be able to comprehend the vocabulary used in the piece of writing. If the individual words don't make the sense then the overall story will not either. Learners can draw on their prior knowledge of vocabulary, but they also need to continually be taught new words. The best vocabulary instruction occurs at the point of need. Parents and teachers should pre-teach new words that a child will encounter in a text or aid her in understanding unfamiliar words as she comes upon them in the writing. In addition to being able to understand each distinct word in a text, the child also has to be able to put them together to develop an overall conception of what it is trying to say. This is text comprehension. Text comprehension is much more complex and varied that vocabulary knowledge.

At the most basic level reading is the recognition of words. From simple recognition of the individual letters and how these letters form a particular word, to what each word means - not just on an individual level, but also as part of a text. In English, as in many other languages, different combinations of the same letters can be used to form different words with completely different meanings. So, the letters $\mathrm{t} \mathrm{c}$ a can make both cat (an animal that goes miaow) and act (which has a number of meanings, from 'do something', to 'behave in certain ways', to 'perform in a play or film'). Recognition of the actual word is not enough on its own to constitute reading.

\footnotetext{
${ }^{1}$ Jeremy Harmer. The practice of teaching English. Longman third edition. 2011.P.-210
} 
In other words, there are multiple reasons why someone might read a text. But working out the purpose is a key factor when it comes to teaching reading. Why we are reading something will make a difference to how we read it and in what depth. When we are teaching reading in class we have to begin by asking ourselves a series of questions in order to make the lesson as effective as possible. It is not good enough to just hand the students a text with a set of questions, ask them to read the text and answer the questions, and think that we are actually teaching them something. Any learning that takes place in such a lesson will be incidental and not because of the teaching. So, planning our reading lessons is essential, and we need to make sure that our aims are clear and that the text and tasks are appropriate. In many cases we can relate our questions to what we do in real life with the type of text we choose. In other words, what do we read in real-life situations? Why do we read these texts? What is the purpose of the writer and of the reader? How do we read the text in order to get what we need from it? So when we teach how to read the text in class we want to try and replicate as much of the real situation as possible. Firstly, we need to give the students information as to where they are, what their destination is, etc. We may also want to focus their attention on the context, and we could use a short listening text where someone is doing exactly what they will do - trying to find their train. Finally, we can give them a copy of the timetable and a short time limit in which to find the relevant information.

The way we read the texts is different because the purposes are different. The strategies we employ are designed to get the information we want from the text in the most effective way. It is not simply a matter of skimming or scanning, but a set of far more complex things. Therefore, in the classroom, we need to mirror these real-life texts and strategies. We need to help our students use the right approaches to reading even if the language is new or difficult. To do this we need to ask questions and promote awareness, and not simply employ basic

As it stated above, reading comprehension is incredibly complex and multifaceted. Because of this, readers do not develop the ability to comprehend texts quickly, easily or independently. Reading comprehension strategies must be taught over an extended period of time by parents and teachers who have knowledge and experience using them. It might seem that once a child learns to read in the elementary grades he is able to tackle any future text that comes his way. This is not true. Reading comprehension strategies must be refined, practiced and reinforced continually throughout life. Even in the middle grades and high school, parents and teachers need to continue to help their children develop reading comprehension strategies. As their reading materials become more diverse and challenging, children need to learn new tools for comprehending these texts. Content area materials such as textbooks and newspaper, magazine and journal articles pose different reading comprehension challenges for young people and thus require different comprehension strategies.

There may be a question as "Why reading comprehension is important?" It is clear that without comprehension, reading is nothing more than observing symbols on a page with your eyes and sounding them out. Imagine being handed a story written in Egyptian hieroglyphics with no understanding of their meaning. You may appreciate the words aesthetically and even be able to draw some small bits of meaning from the page, but you are not truly reading the story. The words on the page have no meaning. They are simply symbols. People read for many reasons but understanding is always a part of their purpose. Reading comprehension is important because without it reading doesn't provide the reader with any information. 2

Reading is an interactive process between the reader, the text and the context in which the text is presented. The most important component here is the reader. The reader gives meaning to the text, not the other way around. The reader's prior knowledge determines what meaning he will derive from his interaction with the text. But here, the context plays a big role as well since it sets the purpose or instruction for reading. The purpose for reading should be built on what the reader already knows, and then relate it to something that he needs to find out in the text.

The Simple View of Reading states that Reading Comprehension is a product of Decoding and Linguistic Comprehension. Therefore, when reading, we don't use just the top-down or bottom-up processing. We use both processes depending on our needs. Any available information is processed and used simultaneously to create meaning. LC is essentially dependent on how much the reader knows because that's where he will draw out meaning for the text he is decoding. Consequently, as one's

\footnotetext{
2 Jeremey Harmer. The practice of teaching English. Pearson. Longman.2011.P.-213
} 
knowledge base increases, LC, and later on reading comprehension increases too. That's why developing a Genuine Love for Reading (GLR) among children is very crucial. Once you have readers who have the intrinsic motivation to read, your LC part is taken care of. Plus, they will have more opportunities to practice the $\mathrm{D}$ part. To ensure comprehension, reading should be relevant to the reader.

Reading used to be seen only as the ability to recognize and say each separate word in a text using our knowledge of letters and sounds. We now know that reading is much more than simply decoding each word. Now we think of reading as being able to get meaning from the text, even if we cannot read every single word. It is even possible for some children to be able to decode a text but not to understand what they are reading at all. Marie Clay, a world recognized specialist on reading, says that 'reading is a meaning-making, problem-solving activity .3 From this we can see that children must both decode and make meaning from what they read.

Children need to be taught to decode text even though this is not the only skill they need. They need to know the letters of the alphabet, the sounds that each letter makes and what sounds groups of letters make. They need to know how to sound out a new word by breaking words into their different sounds and hearing how the sounds flow together to make a word. Children need some general knowledge to make meaning from what they read. The more they already know about the topic they are reading about, the easier it will be to add to that knowledge and get meaning from it. For example, reading about a camel is meaningless if children do not know what a camel is. Children need to know the language in which they are reading. Knowledge of language helps us understand what we read and it helps us with words we do not know. When we know the language, we can predict what kinds of words will come next in a meaningful sentence. Children need to know sufficient sight words or high-frequency words and key vocabulary words. If they read too slowly they will forget what they read at the beginning of the sentence by the time they get to the end, and lose the meaning.

From this we can see that in order to read meaningfully, children need to combine their knowledge about decoding, their knowledge of the language in which they are reading, their general knowledge of the world around them and their recognition of sight words and vocabulary words. When children amalgamate, organize and control these types of knowledge they are able to respond to what they read with both pleasure and curiosity because it is ultimately meaningful to them.

Learning how to read is primarily a matter of learning how to organize and integrate knowledge effectively. It is control of the orchestration process rather than just the possession of knowledge that determine the degree of reading skill. To learn to read in a language that is familiar to them and then, when they are ready, they can learn in an additional language.

It is well known that children who do not learn to read and write in the first three years at school find it very difficult for them to ever catch up. Since reading comprehension underpins all learning in all subjects, children need to master reading from the beginning of their schooling to prevent being disadvantaged at school. Reading is a complex process that involves many skills. These need to be developed over time as children progress through both primary and high school to ultimately attain an advanced reading level that will enable them to cope with tertiary education and the ever-increasing demands of the modern world.

Children are unique and they all have different learning styles and individual needs. We need to be aware of this when we consider the different methodologies we use to teach reading. There is no one fixed method that will successfully teach all children to read. Therefore the best way to teach reading is through a variety of teaching methods using stories and books. These teaching methods, supported by relevant book provision, underpin the NCS and outcomes-based education that give priority to understanding and the ability to apply knowledge.

\section{CONCLUSION}

The skill of reading is an enabling skill, allowing access to a world of experience far beyond the perceived realities of one's immediate surroundings. Moreover, the method of gaining access to this world is a uniquely reflective process as compared with the access afforded by radio, movies, or television. Teachers require enough books to suit every child's reading level and to develop their

${ }^{3}$ Carrell, P.L 'Evidence of a formal schema in second language comprehension. Blackwell publishing. 2003.P-42 
independent reading skills. There should be sufficient books for children to be able to take books home to read every day.

* Reading activities refer to any activity classroom instructors use to help the learner bring their background knowledge to connect with the new information they encounter in the reading in order to get the most understanding of the message in the reading material. Reading activities in the present study refer to guessing reading content from pictures, and pre-reading questioning activities the researcher used to stimulate the learners' use of their schema.

* Reading comprehension refers to the learners' level of reading comprehension ability which was measured by the scores sought from the tests taken before the implementation of the 2 pre-reading activities.

* Satisfaction refers to the learners' like and dislike towards the incorporation of 2 pre-reading activities (guessing reading content from pictures, and pre-reading questioning activities) in learning reading comprehension. The learners' satisfaction level in the present study was measured by the scores obtained from the questionnaire administered after the experiment.

\section{REFERENCES}

1. Lolakhon Khamidovna Nigmatova and Gudzina Viktoriya Anatolyevna 2020. Expression of language, culture and spirituality in world explanatory dictionary. International Journal on Integrated Education. 2, 6 (Mar. 2020), 101-105. DOI:https://doi.org/10.31149/ijie.v2i6.126.

2. Zaripova , D.B. 2020. The role of didactic works in world literature. International Journal on Integrated Education. 3, 2 (Feb. 2020), 10-14. DOI:https://doi.org/10.31149/ijie.v3i2.3.

3. Nafisa, K. M. (2020). PHILOSOPHICAL OUTLOOK OF NASIR TUSIY. American Journal of Social and Humanitarian Research, 1(1), 59-61. Retrieved from https://www.grnjournals.us/index.php/AJSHR/article/view/107

4. Nosirova Dilfuza Mustafoyevna 2020. Formation of written speech in foreign language lessons. International Journal on Integrated Education. 3, 1 (Mar. 2020), 123-125. DOI:https://doi.org/10.31149/ijie.v3i1.56. 